Artigos

Volume 7 - 2017| n. 10

\title{
Os Ordenados Pagos aos Professores de Primeiras Letras às Políticas de Valorização Profissional e Social
}

\author{
Eduardo Ferreira da Silva Caetano \\ Universidade de Brasília (UnB), Brasília/DF - Brasil
}

\section{Resumo}

O artigo busca evidenciar as políticas de reconhecimento e valorização dos professores no processo histórico e propõe-se a analisar a fixação de ordenados insuficientes pagos aos professores de primeiras letras em Minas Gerais, bem como as políticas de reconhecimento profissional criadas pelos governos mineiros para a profissão do professor. Investiga ainda, no percurso histórico mineiro, alguns elementos que revelam como o professor passa a ser um trabalhador e as primeiras remunerações fixadas pelos governos e os tributos criados para financiar a educação. Por fim, desvela como os governos mineiros reconheciam a profissão, fixavam os salários e avaliavam as lutas pela constituição da carreira do professorado entre 1900 e 2014.

Palavras-chave: Valorização dos professores. Ordenados insuficientes. Processo histórico.

\section{The Wages Paid to Elementary School Teachers to the Policies of Professional and Social Valorization}

\begin{abstract}
This article seeks to highlight the policies of recognition and appreciation of teachers along the historical process. It also aims to analyze the establishment of low wages paid to Elementary School teachers in Minas Gerais, as well as the policies of professional recognition created by the state governments for the profession of teacher. It also investigates, in the history of Minas Gerais, some elements that reveal how teachers becomes workers and the initial wages set by the governments and the taxes created to finance education. Finally, it unveils how the Minhas Gerais governments recognized the profession, set wages and evaluated the struggles for the constitution of the professorship between 1900 and 2014.
\end{abstract}

Keywords: Teacher appreciation. Low wages. Historical Process. 
Os Ordenados Pagos aos Professores de Primeiras Letras às Políticas de Valorização Profissional e Social

\section{Os Ordenados e a Baixa Remuneração dos Professores das Primeiras Letras em Minas Gerais}

Em 1549, chega à Bahia o primeiro governador geral, Tomé de Souza, com numeroso séquito de degredados, marujos, funcionários, algumas famílias e suas respectivas proles e meninos órfãos de Lisboa. Segundo Monlevade (2000), os religiosos eram quatro padres e dois irmãos, coadjutores da recém-fundada Companhia de Jesus. Manoel da Nóbrega era o Superior enviado ao Brasil a mando de Inácio de Loyola. Após entendimentos entre o Provincial Simão Rodrigues e o rei de Portugal, os religiosos se tornaram os primeiros professores de primeiras letras.

Já em 1550, fundou-se o Colégio dos Meninos de Jesus junto com a dotação inicial oriunda da Real Fazenda de Lisboa e criou-se um subsídio remunerado de $2 \$ 400$ para o sustento dos padres em sua missão catequética. O pagamento, na maioria das vezes, era feito com alimentos, sendo uma espécie de autofinanciamento para educação. Segundo o estudioso Monlevade (2000), as despesas correntes do colégio no sustento dos religiosos derivavam crescentemente da produção das chácaras e fazendas que passaram a gerar dinheiro com a venda de animais e alimentos.

Até 1759, quando foram expulsos do Brasil, os jesuítas haviam fundado dezessete colégios e cerca de duas centenas de escolas de primeiras letras na maioria das capitanias. Existiam escolas mantidas por outras ordens religiosas, mas as jesuíticas eram as escolas oficiais que ofereciam o ensino gratuito do Estado português conduzido pela Igreja católica. Em sua maioria, os professores entre 1549 e 1759 eram religiosos que passaram por privações e necessidades (MONLEVADE, 2000).

Com o decorrer dos anos, entre 1759 e 1771, os mestres eram pagos pelas câmaras municipais, que possuíam autorização para cobrar contribuições dos pais dos alunos. Os problemas com a falta de pagamentos levavam as oscilações nos ordenados, o que gerava insatisfação por parte dos professores (FERNANDES, 1994).

Ainda em 1772, o subsídio literário ${ }^{1}$ imposto - em que os recursos deveriam ser usados para o pagamento dos ordenados dos professores - incidia sobre o vinho, o vinagre, a aguardente e a carne fresca. As Juntas da Real Fazenda, estabelecidas em todas as capitanias, eram as responsáveis pela administração do tributo e pelo pagamento dos mestres. Segundo o pesquisador Machado (1972), essas juntas elaboravam o balanço geral, que era remetido à Junta de Administração e Arrecadação do subsídio literário que, por sua vez, encaminhava as contas a Lisboa.

Depois da expulsão dos jesuítas e da implantação das aulas régias pelo Marquês de Pombal, em 1772, o professor passou a receber ordenados, devido às disputas da lgreja católica com o primeiro-ministro de Portugal, Sebastião José de Carvalho e Melo para a condução dos interesses na colônia (CARRATO, 1968). As aulas régias foram financiadas pelo Estado português com a criação dos tributos públicos oriundos do subsídio literário cobrado pelas câmaras municipais sobre a produção da carne fresca, da produção de vinho

1 O subsídio literário foi um imposto português criado pelo Alvará de 10 de novembro de 1772. Esse imposto custeava as despesas e as reformas da instrução pública promovidas pelo Marquês de Pombal (CARVALHO, 2010). 
Os Ordenados Pagos aos Professores de Primeiras Letras às Políticas de Valorização Profissional e Social

e da destilação da cachaça. Esse subsídio não era recolhido regularmente e, com isso, os recursos acabaram sendo insuficientes para os propósitos originais.

Ressalta-se ainda que as verbas do subsídio literário foram utilizadas para pagar os ordenados dos professores do Real Colégio dos Nobres, em Lisboa, determinadas pelo Decreto de 16 de junho de 1792. A utilização das verbas desse tributo para pagamento de professores em Lisboa provocava baixos ordenados e atrasos nos pagamentos dos professores brasileiros (ADÃO, 1997).

Com estes registros, partimos para o interior de Minas Gerais entre os anos de $1795 \mathrm{e}$ 1850, para revelar elementos referentes ao pagamento dos salários dos mestres conforme sua cadeira. Os professores de Filosofia recebiam $460 \$ 000$ réis a cada ano, os de Retórica, $440 \$ 000$, os de Gramática Latina, $400 \$ 000$ e os de Primeiras Letras, $150 \$ 000$, sendo os ordenados dos professores das primeiras letras o menor em comparação com os das demais categorias (ADÃO, 1997).

De acordo com os estudos de Adão (1997), durante o Período Colonial, havia constantes queixas por parte da população, que reclamava de professores que deixavam de comparecer às aulas para trabalhar em outra atividade e melhorar a renda. Em 1797, além de baixos salários, os professores reclamavam do não recebimento dos salários. Alguns mestres ficavam anos sem receber os ordenados. A pesquisadora Cardoso (2002) destaca o caso do mestre de latim José Elói Ottoni, da Vila de Bonsucesso de Minas, que estava há quatro anos sem receber salário e, como não encontrava solução para o problema, foi pessoalmente a Lisboa requisitar seu pagamento.

Os professores de primeiras letras eram os que recebiam os menores salários, e o número absoluto de ocorrências de salários incompletos também era mais frequente entre eles. No período de 1795 e 1797, havia sete professores de primeiras letras nessa situação de salários atrasados: $15 \%$ do total de 46 cadeiras a cada ano e $21 \%$ do total de 33 cadeiras de primeiras letras.

Em 1800, em Vila Rica, Bernardo José de Lorena, governador da capitania, queixavase da diminuta arrecadação do imposto destinado ao pagamento dos mestres. Em 1827, o conselheiro Vasconcellos expôs ao conselho do governo da Província de Minas Gerais o plano para o melhoramento da instrução. Naquele período foi proposta:

Reforma dos salários, com justificativa de que os mestres tinham um salário muito limitado. Esse princípio não foi aplicado aos mestres de primeiras letras, pois a constituição no artigo 179 garantia a gratuidade da instrução primária. Por isso, propôs salário aos mestres de primeiras letras de $100 \$ 000$ e com o acréscimo de título de gratificação poderia chegar a $300 \$ 000$ (SALES, 2008, p. 87).

Segundo Sales, os salários dos professores de primeiras letras eram inferiores aos dos demais professores na Província de Minas Gerais, e havia mais escolas de primeiras letras particulares do que públicas. Em 28 de março de 1835, a Assembleia Legislativa da Província de Minas Gerais aprovou a Lei $n^{\circ} 13$ (MINAS GERAIS, 1835), que regulamentava as regras para a implantação da instrução pública primária e secundária na Província de Minas Gerais.

Assim, os professores estavam submetidos a uma regulamentação desde o ano de 1835, quando a primeira lei sobre o ensino no estado apontava as obrigações dos professores e discorria sobre sua formação, determinando a criação de escolas normais. Na prática, se 
Os Ordenados Pagos aos Professores de Primeiras Letras às Políticas de Valorização Profissional e Social

observou uma desarticulação entre os ideais de organização escolar e sua aplicabilidade, justificada pela falta de condições materiais e de viabilidade (KULESZA, 1998).

Passados alguns anos, a acumulação de atividades tornou-se uma prática costumeira adotada pelos professores e mestres e toleradas pelas autoridades. Esses mestres "[...] se ocupavam em atividades mecânicas, como, por exemplo, alfaiates, sapateiros, barbeiros" (ADÃO, 1997, p. 226). No Brasil, após 1822, seguiram-se os debates sobre a instrução pública, sendo que o imposto do subsídio literário continuou a ser cobrado até o ano de 1834 . Em 1823, criticavam-se as baixas remunerações dos professores primários e as justificativas pela impossibilidade do Estado em pagar melhores ordenados aos mestres.

O parágrafo XXXII do artigo 179 da Constituição de 1824 previa: "[...] a instrução primária e gratuita a todos os cidadãos" e a Lei de 15 de outubro de 1827 (BRASIL, 1827), assinada por D. Pedro I, no artigo $1^{\circ}$, que "[...] em todas as cidades, vilas e lugares mais populosos, haverá as escolas de primeiras letras que forem necessárias". $O$ artigo $3^{\circ}$ instituiu os ordenados dos professores entre duzentos a quinhentos mil réis anuais. Nas palavras de Sucupira (2001, p. 59), a remuneração era "[...] irrisória que na maior parte das vezes não atingia o nível máximo fixado na lei”.

Para viabilizar oferta de vagas para os alunos e reconhecer a necessidade do professor, a Lei de 1827 fixou os ordenados dos professores, a forma de ingresso e a obrigatoriedade de exercício exclusivo do magistério. Devido à remuneração baixa e aos valores estipulados em lei, acentuou-se o desinteresse por parte dos professores. Assim, era admitida qualquer pessoa com boa conduta e autodidática, independentemente de sua formação para ser professor. Os relatórios do ministro do império Lino Coutinho, entre 1831 a 1836, mostram os resultados e a má condição do ensino de primeiras letras no país.

Esses elementos revelam as condições de trabalho dos professores. Percebe-se, nos relatórios, que os ministros apontavam para a ocorrência de desleixos do poder público em relação à educação. Os estudos de Silva (2009) apontam que no "Império era constante nos discursos e nas ações do ministro da instrução pública a desorganização, insuficiência de recursos financeiros destinados ao ensino" (SILVA, 2009, p. 97). Esses fatos evidenciam que foram marcas presentes no Império e que percorreram séculos.

Ainda a Lei de 1827 normatizou questões relativas à formação e aos ordenados para o docente, pois quem dominasse os conteúdos discriminados na lei poderiam ensinar. Essa lei regulou os ordenados dos professores em $200 \$ 000$ a $500 \$ 000$ anuais $^{2}$ e ainda igualou os salários dos professores aprovados em concurso para o ensino primário, mas permitia que, caso não houvesse aprovação, o governante poderia contratar pessoas com menor instrução e salário menor (VIEIRA, 2007).

Havia diferenças salariais entre professores concursados e não concursados. Conforme destacado por Hilsdorf (1998), em 1828, a primeira professora aprovada em São Paulo recebia $300 \$ 000$ réis anuais, enquanto a professora não concursada recebia $76 \$ 800$ réis

2 Segundo o especialista em cotação de moedas Antônio Luiz Costa sobre a conversão dos réis de 1827 para reais de 2011: 200 mil réis equivalem a $R \$ 8.800,00$ por ano (o que daria um salário mensal de $R \$ 680,00$, mais o $13^{\circ}$ ); 500 mil réis teria um valor aproximado de $R \$ 22.000,00$ por ano: $R \$ 1.700,00$ por mês, mais o $13^{\circ}$ (COSTA, 2017). 
Os Ordenados Pagos aos Professores de Primeiras Letras às Políticas de Valorização Profissional e Social

anuais. A Lei Geral, de 15 de outubro de 1827 estabeleceu exames de seleção para os professores, que eram examinados publicamente perante os presidentes.

Em 1835 foi criada a Escola Normal Brasileira na Província do Rio de Janeiro e Minas Gerais. Seguindo instrução da Lei de 15 de outubro de 1827, cada capital da província deveria ter uma escola normal e nela se habilitariam as pessoas que se destinassem ao magistério da instrução primária. Segundo Tanuri (2000), as contratações ficaram limitadas a saberes de matérias do ensino primário, nomeações políticas e religiosas desprovidas de rigor, o que só atraiu ao magistério professores de baixo nível.

As dificuldades das primeiras escolas normais e os modestos resultados produzidos propiciou desprestígio a essa escola, a ponto de alguns presidentes de províncias e inspetores de instrução a rejeitarem como instrumento para qualificação de pessoal docente (KULESZA, 1998). Por volta de 1880 , a remuneração era tão baixa que só poderia exercê-la quem tivesse outra atividade.

\section{As Políticas Profissionais e os Salários Pagos aos Professores na Província de Minas Gerais}

A Instrução na Província de Minas Gerais por meio do Regulamento $n^{\circ} 41$, de 16 de maio, de 1857 determinou, no artigo 22, que os professores recebessem quotas pré-definidas dos cofres provinciais, a título de aluguel de casas, quando não houvesse em suas localidades prédios públicos que abrigassem as aulas.

A lei permitia ainda que os mestres habitassem a mesma casa que serviria de escola. As leis orçamentárias, entre 1850 a 1889, e os valores para a manutenção das escolas eram significativos. No ano de 1885, a despesa com a instrução consumia $31,9 \%$ das despesas provinciais. Seus valores são inferiores apenas aos montantes destinados à segurança e às obras públicas. Mesmo abarcando um percentual da receita provincial, esses valores continuavam aquém das necessidades da província, em termos de atendimento à demanda escolar (FARIA FILHO, 1998).

Os pagamentos dos salários aos professores eram baseados nos mapas de frequência dos alunos: caso os professores não preenchessem os mapas de acordo com as determinações legais, ficariam sem receber. Segundo Faria Filho (1998), muitos professores lançavam nos mapas apenas o número mínimo exigido de alunos, mesmo que não fossem frequentes às aulas.

Em 1859, foi publicado o Regulamento $n^{\circ} 44$, que determinou a compra de utensílios e objetos necessários ao ensino, como mesas e cadeiras, que seriam comprados pelos professores, pais de família e membros residentes no local da escola. Segundo Andrade e Carvalho (2009), com a carência de materiais básicos, os próprios moradores e professores deveriam mobiliar a escola com os materiais necessários. O Manifesto dos Professores Públicos Primários da Corte, de 1871, destacou que o professor "[...] só dispunha de $66 \$ 666$ para pagar casa, sustentar mulher e filhos, pagar médico e botica, etc." (MANIFESTO...,1871, p.19).

Diante dessas dificuldades financeiras, o governo da Província de Minas Gerais fez o Regulamento $n^{\circ} 84$, de 21 de março de 1879, que estabeleceu as caixas escolares. O objetivo era o depósito de valores vindos de multas, donativos e quotas do orçamento provincial e 
Os Ordenados Pagos aos Professores de Primeiras Letras às Políticas de Valorização Profissional e Social

municipal para a aquisição de materiais e utensílios necessários ao ensino de meninos pobres. O presidente do estado de Minas Gerais, Antônio Gonçalves Chaves, no dia $1^{\circ}$ de agosto de 1884, mencionou que a instituição da obrigatoriedade de escolas normais dificultou a habilitação para o magistério e, por isso, diminuíram as cadeiras ocupadas por professores. Em 1885, no Relatório $n^{\circ} 100$, o mesmo governo autorizou remuneração diferente aos professores da instrução pública mineira, conforme comentário no relatório da Inspetoria Geral de Ouro Preto:

Os professores normalistas de $2^{\circ}$ grau percebem de vencimentos 1:050\$000, e os de $1^{\circ}$ grau 800\$000; os não normalistas de $2^{\circ}$ grau $960 \$ 000$, os de freguesias $720 \$ 000$ e os de distritos $600 \$ 000$. A diferença entre os vencimentos dos de $2^{\circ}$ grau é apenas de $90 \$ 000$, e entre os de $1^{\circ}$ grau de $80 \$ 000$, para os de freguesias e de $200 \$ 000$ para os de distritos. Além destas notam-se outras desigualdades. Os professores da escola normal de São João Del Rey têm apenas a gratificação de $500 \$ 000$, ao passo que o porteiro tem $600 \$ 000$. Os professores do Liceu Mineiro têm 1:960\$000, os dos externatos percebem também 1:200\$000 (MINAS GERAIS, 1885, anexo D, p. 20).

Nesse período imperial, para se candidatar ao cargo de professor público primário, eram necessárias comprovação de idade mínima, boa moralidade e capacidade profissional. $\mathrm{Na}$ República, o Decreto $n^{\circ} 516$, de 12 de junho de 1891 (MINAS GERAIS, 1891), instituiu que o candidato também deveria provar estar isento de crimes, além de possuir boa aparência e isenção de moléstias incompatíveis com o exercício do magistério.

No dia 15 de julho de 1896, no discurso do presidente de estado Chrispim Jacques Bias Fortes ao Congresso Mineiro, há as seguintes palavras:

\begin{abstract}
Infelizmente nem sempre têm os professores provisórios as habilitações precisas para o magistério. Não tendo a administração do Estado um critério ou base segura para avaliar as habilitações deles senão depois de nomeados, não tem meios para impedir que sejam feitas algumas vezes nomeações para esses cargos de indivíduos mal preparados para o mister a que se propõem (MENSAGEM, 1896, p. 22).
\end{abstract}

Percebe-se que o governo tenta afastar a responsabilidade de sua administração pela nomeação de professores mal preparados, por atribuir que só após as nomeações era possível avaliar suas habilidades. No entanto, Tanuri (2000), Faria Filho (2000) e Saviani (2008) explicitam a fragilidade no processo de escolha e nomeação, os baixos salários oferecidos, a falta de formação continuada e a inexistência de política, que afastava os indivíduos qualificados de exercerem a profissão de professor.

O artigo $n^{\circ} 9$ da Lei $n^{\circ} 221$, de 14 de setembro de 1899, instituiu a organização das cadeiras, ao determinar que, nas sedes dos municípios, funcionariam as escolas do mesmo sexo em um só prédio (MINAS GERAIS, 1899, p. 15). No governo de Silviano Brandão (18981902), houve cortes nos gastos com a educação devido à crise econômica que assolou Minas Gerais. Nessa situação, a remuneração de professores da instrução primária passou a ser regida pela Lei $n^{\circ} 221$, de 14 de setembro de 1897, que determinava aos professores de instrução primária com exercício efetivo de mais de 10, 15 ou 20 anos a gratificação anual de $5 \%, 10 \%$ e $15 \%$ sobre seus atuais vencimentos.

Em diferentes momentos, professores vieram a público apontar problemas e queixas, colocando-se nos debates que envolviam a educação. Suas posições e atitudes levaram à reflexão sobre o papel do professor dentro de um projeto na sociedade. 
Os Ordenados Pagos aos Professores de Primeiras Letras às Políticas de Valorização Profissional e Social

\section{A Política de Valorização Profissional do Século XX para os Professores Mineiros}

Durante os anos de 1900 a 1930, as escolas se mantiveram de forma precária em virtude da falta de recursos para a manutenção das cadeiras de ensino elementar. Pelo Decreto $n^{\circ} 1.348$, de 8 de janeiro de 1900 (MINAS GERAIS, 1900), promulgado pelo então governador Francisco Silviano de Almeida Brandão, decretou-se que as salas seriam heterogêneas e que o professor deveria manter na mesma sala os alunos com idades diferentes - de 7 a 13 anos. Esse mesmo decreto previa, como penalidades impostas aos docentes, multas, demissões, admoestações e suspensão dos vencimentos (FARIA FILHO, 2000; GONÇALVES, 2004).

O Decreto $n^{\circ} 1.348$ proibiu que os docentes tivessem outras ocupações além do magistério e assim prevaleceu até o ano de 1911. Os professores que descumprissem essa ou qualquer outra norma estabelecida nas legislações poderiam ser penalizados, e cabia ao Estado o direito de responsabilizar o funcionário pelo mau exercício da função pública. As consequências por ignorar, burlar ou desconhecer as legislações poderiam variar de acordo com a gravidade da irregularidade cometida pelo docente e iam desde uma advertência até a demissão do cargo (MINAS GERAIS, 1900).

Ainda em 1900, ocorreram mudanças na remuneração dos professores mineiros das escolas primárias públicas. Os normalistas que trabalhavam nas escolas urbanas passaram a receber 2:160 $\$ 000$, enquanto os não normalistas, $1.560 \$ 000$. Já os professores normalistas das escolas distritais e coloniais passaram a receber $1.680 \$ 000$, e os que não eram normalistas ganhavam 1.320\$000 (BONACINI, 1992).

Nesse período, o Secretário de Estado dos Negócios do Interior, Wenceslau Braz Pereira Gomes, reduziu o número de escolas primárias de 2.157, em agosto de 1899, para 1.476 após a Lei $n^{\circ} 281$, de setembro de 1899. Dessas escolas, 476 eram urbanas e 1.000 , distritais. Das 1.476 escolas de instrução primária, 661 eram para o sexo masculino, 634 para o sexo feminino e 181 eram mistas (MINAS GERAIS, 1899).

Em 1906, foi fundada em Belo Horizonte a primeira associação de professores do estado, denominada União do Magistério Mineiro. A Lei $n^{\circ} 439$, de 28 de setembro de 1906, sancionada pelo governador João Pinheiro, reformou o ensino primário em Minas Gerais, criando os grupos escolares e, segundo Gonçalves (2006), a organização desse novo sistema de ensino se deu:

[...] com uma concentração de crianças em um mesmo prédio escolar, distribuídas em, pelo menos, quatro salas de aula, obedecendo à seriação e à hierarquização da aprendizagem e, ainda, sob a orientação de um novo método de ensino grupo escolar, demandou uma reestruturação do programa para atender aos novos objetivos do ensino primário (GONÇALVES, 2006, p. 66).

A reforma do presidente mineiro João Pinheiro teve como objetivo difundir a escola primária no estado de Minas Gerais, bem como visualizar e possibilitar a formação da cidadania tutelada. Em 1906, para aumentar a oferta de vagas e melhorar a qualidade do ensino oferecido nas escolas sem aumentar os gastos, o governador mineiro João Pinheiro fixou a política de conscientizar o professor de sua posição social como braço do estudo para 
Os Ordenados Pagos aos Professores de Primeiras Letras às Políticas de Valorização Profissional e Social

a educação do povo. Argumentando escassez de recursos, não ofereceu aumento salarial, mas tencionava oferecer uma boa educação à população (DURÃES, 2002).

No governo de Bueno Brandão, de 1910 a 1914, o Decreto n 319, aprovado em 1911, determinou normas para a carreira docente. Esse Decreto definiu que os docentes que tivessem em suas escolas mais de vinte alunos aprovados nos exames finais receberiam uma gratificação de $200 \$ 000$ por aluno que excedesse de vinte. Determinou também, as seguintes recompensas: gratificação de $480 \$ 000$ para nomeação ao cargo de inspetor municipal, $20 \%$ de gratificação sobre os vencimentos para os professores rurais, direito a visita aos grupos escolares ou viagem à capital e, por fim, elogios em portaria. Para receber a gratificação de $200 \$ 000$, o aluno deveria ter começado e terminado o curso com o mesmo professor.

Em 27 de setembro de 1919, o então presidente de Minas Gerais, Artur da Silva Bernardes, aprovou a Lei $n^{\circ} 752$ (MINAS GERAIS, 1919), que fixou a exigência do diploma de normalista para a investidura de cargo no magistério. Um ano depois, em 27 de setembro de 1920, Artur Bernardes sancionou a Lei $n^{\circ} 800$, que priorizou a nomeação de professoras normalistas, solteiras ou viúvas e sem filhos. O governo priorizava a professora solteira, por acreditar que, sem as obrigações domésticas, ela poderia se dedicar com mais intensidade à educação de seus alunos (MINAS GERAIS, 1920).

Em 1927, o Ministro da Educação Francisco Campos empreendeu a renovação do ensino público, criando a Escola de Aperfeiçoamento para professores diplomados pelas escolas normais comuns, em Belo Horizonte. Em 1930, Olegário Maciel assumiu a presidência do estado de Minas Gerais e criou a Escola de Aperfeiçoamento e Formação de Professores, com o objetivo de melhorar a qualidade do trabalho tanto dos professores da capital quanto dos de várias partes do estado.

Nos anos de 1930 a 1945, em Minas Gerais, durante a Era Vargas, os professores vivenciaram a situação de aparente reconhecimento social e profissional. Em janeiro de 1931, - Ministério da Educação e da Saúde despachou um ato suspendendo o ensino em 355 escolas rurais, 12 escolas urbanas e 26 escolas noturnas. Justificou-se o ato por falta de frequências, carência de matrículas e falta de prédios escolares. Além disso, em março de 1931, o Decreto $n^{\circ} 9.892$ (MINAS GERAIS, 1931) classificava as escolas primárias em quatro níveis, de acordo com os quais a remuneração do professorado variava.

Por outro lado, a Associação das Professoras Primárias de Minas Gerais (APPMG) iniciou suas atividades em 27 de agosto de 1931, tendo como objetivo apoiar o poder público. Em discurso na cerimônia de posse da primeira diretoria, o inspetor geral da instrução pública Carlos de Campos afirmou que o "[...] governo do estado tinha boa vontade em dar aos professores mineiros boas condições de trabalho, no entanto, não oferecia devido ao momento de crise econômica e financeira" (ASSOCIAÇÃO...1931-1939, p. 4).

$O$ inspetor geral afirmou que a crise econômica e financeira que o Estado enfrentava justificava a falta de políticas de reconhecimento para o professor e os baixos salários na instrução pública. Com isso, pediu a compreensão e o sacrifício do professorado para continuar a trabalhar com carinho e dedicação, a fim de manter uma escola eficiente e produtiva (OLIVEIRA, 2008). Essa realidade confirma a interpretação de Cury (2000) de que a ampliação da oferta e do acesso à educação foi garantida por um corpo docente que sofreu o ônus com rebaixamento salarial, duplicação da jornada de trabalho, ingresso por concurso reduzido e elevação de profissionais submetidos à prática de contratos precários. Assim, os 
Os Ordenados Pagos aos Professores de Primeiras Letras às Políticas de Valorização Profissional e Social

professores realizaram suas atividades "[...] cada vez com mais esforço, em condições que, no melhor dos casos, são estáveis e, no pior, estão se deteriorando" (OLIVEIRA, 2008, p. 72).

No ano de 1942, a APPMG se mobilizou para conseguir novos salários para as professoras e a revisão nos critérios para acesso e promoção na carreira de magistério. Peixoto (2003) destaca que, nesse período, os professores tiveram uma perda de valor de $100 \$ 00$, que representava $30 \%$ do salário, e a renda ficou congelada por vários meses. Nesse sentido, segundo Guimarães (1940), o poder aquisitivo baixo dos professores primários dificultava o aprimoramento e o acesso a conhecimentos recentes, pois o livro quase sempre era muito caro. Poucos eram os municípios mineiros que tinham bibliotecas (GUIMARÃES, 1940, p. 33).

A desvalorização profissional decorrente dos pagamentos de baixos salários na década de 1940 não permitia a esses profissionais a aquisição de livros que os ajudassem a desenvolver melhor seu trabalho. Essa realidade confirma o que adverte Kuenzer (1999), que os professores empregam seus esforços para aprender por si só, selecionar conteúdos, desenvolver as formas metodológicas e avaliativas mais adequadas para atender à diversidade de alunos, sem que, para isso, Ihe sejam disponibilizadas as condições materiais, pedagógicas e financeiras.

Anos mais tarde, Juscelino Kubitschek de Oliveira, como governador de Minas Gerais, sancionou a Lei no 869, de 05 de julho de 1952 (MINAS GERAIS, 1952), que dispôs sobre o estatuto dos funcionários públicos civis do estado. Foram regulamentadas as condições de provimento dos cargos públicos, os direitos, as vantagens, os deveres e as responsabilidades dos funcionários civis. A professora primária foi lembrada, quando lhe foi assegurado o direito de licenciar-se para acompanhar o marido servidor federal, estadual ou militar, em casos de remoção.

Em 1968 e 1969, ocorreram duas greves seguidas dos professores durante o governo de Israel Pinheiro da Silva. Esses profissionais reivindicavam o pagamento de salários atrasados, pois em alguns municípios os professores primários estavam de seis meses a um ano sem receber salários (BONACINI, 1992).

Em 1970, os cargos da educação foram reorganizados em: diretor de escola primária I, diretor de escola primária II, técnico de ensino primário, orientador do ensino primário, inspetor escolar, professor de ensino primário, professor de escola rural, servente de grupos, auxiliar de serviço, vigia e professor. Com a aprovação da Lei n 5.692 (BRASIL, 1971), que fixou as diretrizes e bases para o ensino de $1^{\circ}$ e $2^{\circ}$ graus, os professores mineiros iniciaram um processo de cobrança do cumprimento dos pontos referentes à valorização do magistério, entre eles, o Plano de Carreira e o pagamento por titulação independente da área de atuação.

O Sind-UTE/MG foi fundado em 1979 durante congresso dos educadores de Minas Gerais em Belo Horizonte e representa não só os professores da rede estadual de ensino, mas também todos os profissionais que atuam nas escolas. Nesse mesmo ano, o movimento dos trabalhadores da educação, envolvendo a rede particular e outras redes de ensino, fez eclodir uma greve que durou 41 dias e envolveu 420 cidades. Nesse movimento histórico, os professores atuaram e pressionaram o governo mineiro para atender as reivindicações e reconhecer a profissão. 
Os Ordenados Pagos aos Professores de Primeiras Letras às Políticas de Valorização Profissional e Social

\title{
A Política de Valorização para os Professores: embates e tensões
}

Nos anos 2000 em diante, o Governo Federal implementou o Plano Nacional de Educação (PNE - 2001-2011), o Plano de Desenvolvimento da Educação (PDE - 2007), a Lei do Piso e o Fundo de Desenvolvimento e Manutenção da Educação Básica e Valorização dos Profissionais da Educação (FUNDEB), como ações constituintes de política voltada para a valorização e, ainda, como sinal de atendimento das questões referentes à formação e às condições de trabalho dos profissionais em educação (OLIVEIRA, 2004).

O Plano Nacional de Educação de 2001 estabeleceu como uma de suas prioridades e deveres constitucionais a valorização dos profissionais da educação, incluindo formação continuada, condições adequadas de trabalho, salário digno e carreira de magistério. Já o Plano de Desenvolvimento da Educação fixou como um de seus principais pontos:

\begin{abstract}
A formação de professores e a valorização dos profissionais da educação. Nesse sentido, o PDE promove o desdobramento de iniciativas fulcrais levadas a termo: a distinção dada aos profissionais da educação, única categoria profissional com piso salarial nacional constitucionalmente assegurado, e o comprometimento definitivo da União com a formação de professores para os sistemas públicos de educação básica (BRASIL, 2007, p. 16).
\end{abstract}

No estado de Minas Gerais, no início da década de 2000, a política educacional, empregada na gestão do governador Itamar Franco 1998 a 2002, teve como objetivos a busca pela garantia de acesso e permanência do estudante na escola, a implementação de projeto político-pedagógico, a autonomia, a gestão democrática da escola e a procura pela valorização dos profissionais da educação. Criou o Projeto Veredas ${ }^{3}$ para qualificar e habilitar os profissionais da área da educação que ministravam aulas de $1^{a}$ à $4^{a}$ série, e sua gestão focou na continuidade ao conjunto de ações e decisões que marcaram o estado desde o início da década de 1990.

O governador Itamar Franco, embora com o discurso de oposição ao governo federal, manteve a mesma linha de seu antecessor, que seguia a orientação da gestão federal, como política de valorização dos professores. Essa contradição entre a fala de opositor e a prática de continuidade do governador Itamar Franco é observada no Relatório de Gestão 1999 a 2002 em que a "Secretaria de Estado da Educação avaliou os programas e, devido ao sucesso obtido, decidiu ampliá-los, utilizando recursos do tesouro estadual” (MINAS GERAIS, 2002, p. 76).

O governador Aécio Neves (2003-2010) continuou com o Projeto Veredas ${ }^{4}$, ao mesmo tempo em que implementou o choque de gestão. Aplicou ações de racionalização de processos, reestruturação do aparelho do estado e avaliação de desempenho institucional e individual e, além disso, fixou como objetivo reduzir os custos dos serviços públicos. O governador Antônio Anastasia (2010-2014), sucessor de Aécio Neves, além de prosseguir

3 Foi um programa do governador Itamar Franco 1999-2000 junto a Secretaria de Estado de Educação de Minas Gerais para os professores da Rede Estadual e Municipal que atuavam no ensino fundamental nos anos iniciais. Teve a finalidade de oferecer habilitação superior aos professores dos anos iniciais do ensino fundamental que não tinham a formação nesse nível (MINAS GERAIS, 2002, p. 10).

4 Em Minas Gerais, no ano de 2000, havia 60 mil professores em exercício na rede pública do estado sem habilitação em nível superior. Desses, 18 mil estavam em escolas estaduais e 42 mil em escolas municipais (MAGALHÃES, 2005, p. 80). 
Os Ordenados Pagos aos Professores de Primeiras Letras às Políticas de Valorização Profissional e Social

com a gestão deste, adotou ainda o programa chamado "Estado para Resultados" e a remuneração de "pagamento por subsídio" (GUIMARÃES; PORDEUS; CAMPOS 2010).

Essa política educacional no estado de Minas Gerais pouco mudou a realidade dos professores mineiros. Conforme salientado pelas palavras de Oliveira (2004), "[...] o trabalho docente foi reestruturado, dando lugar a uma nova organização escolar, e tais transformações, sem adequações necessárias, parecem implicar em processos de precarização do trabalho docente" (OLIVEIRA, 2004, p. 1.140). Ressalta-se que, nesse período, constatou-se como um efeito das reformas educacionais "[...] aguda precarização da remuneração, da carreira e da jornada de trabalho do professor" (COSTA, 2011, p. 20).

Embora os diversos governadores mineiros afirmassem valorizar a carreira docente, não cumpriram os acordos estabelecidos de valorização da profissão, a ponto de a baixa remuneração conjugada à falta de incentivos fazer "[...] com que muitos professores acumulem mais de um emprego no magistério ou cargo em uma mesma rede, chegando, em alguns casos, a ter três turnos diários de efetivo trabalho" (COSTA, 2011, p. 16).

Tudo isso provocou greves nos anos de 2000, 2002, 2003, 2004, 2005, 2006, 2007 e 2008. Em alguns desses anos, apesar de não terem sido deflagradas greves por tempo indeterminado, houve paralisações de 24 horas durante o ano letivo. Em 2002, após 50 dias de greve, o governo do estado firmou documento de ajuste de conduta com o Ministério Público e enviou à Assembleia Legislativa do Estado de Minas Gerais o Plano de Carreira que, depois de debatido, foi aprovado em 2004. Foram instituídas oito carreiras para os profissionais de educação básica.

Por isso, em 2003, foi suspensa pelo governador a tramitação do projeto de lei do Plano de Carreira para os professores, que já havia sido votado em primeiro turno pela Assembleia Legislativa Mineira. O Secretário de Estado de Planejamento e Gestão, Antônio Anastasia, argumentou que era preciso o choque de gestão para corrigir o desequilíbrio das contas públicas e reduzir o déficit que ameaçava o exercício das atividades. Já a Lei $n^{\circ} 15.293$ (MINAS GERAIS, 2004) definiu as carreiras dos profissionais da educação básica em Minas Gerais e estabeleceu oito, cada uma em níveis de I a VI.

Essa lei de 2004 vinculou a progressão e a promoção do professor à avaliação de desempenho. Passou-se a exigir o curso de ensino superior em curso de licenciatura, de graduação plena, com habilitações específicas em área própria para a docência nas séries finais do ensino fundamental. Para o ensino médio, estabeleceu-se formação superior em área correspondente à docência no nível das séries finais do ensino fundamental e do médio. No ano de 2005 foi sancionada a Lei $n^{\circ} 15.784$ (MINAS GERAIS, 2005), que fixou os vencimentos para a categoria. O salário básico inicial para o professor com licenciatura plena era de $\mathrm{R} \$ 453,96$.

O reconhecimento profissional e social e as leis que asseguram direitos aos professores foram alcançados com muita luta e mobilização. Cada conquista resulta de uma longa caminhada que os professores percorrem para ter sua profissão valorizada. O ano de 2008 foi marcante para a luta e estabelecimento da Lei do Piso, um dos elementos estruturantes da política de valorização dos professores.

No contexto da política nacional, a execução de reformas estruturais, principalmente com a desregulamentação das relações de trabalho, segundo Antunes (1997), se dá com a "[...] subproletarização do trabalho, presente nas formas de trabalho precário, parcial, 
Os Ordenados Pagos aos Professores de Primeiras Letras às Políticas de Valorização Profissional e Social

temporário, subcontratado, terceirizado, vinculados à economia informal entre tantas modalidades existentes" (ANTUNES, 1997, p. 44).

Em 2008, em Minas Gerais, o governador Aécio Neves estava no segundo mandato consecutivo e mantinha em andamento a política de reduzir custos e ampliar os resultados no chamado Choque de Gestão. Segundo Vieira (2012), o ano de 2008 foi marcado por lutas e mobilizações da CNTE pela promulgação da Lei do Piso no Congresso Nacional. Por isso, para que o processo da Lei do Piso "[...] acabasse de forma positiva e que não perdesse todo o acúmulo de discussão e de formulação, era de abreviá-lo. Foi o que ocorreu com o aval de todos os partidos políticos" (VIEIRA, 2012, p. 178).

Entre os anos de 2007 a 2010, ocorreu a aprovação da Lei Federal no 11.738 e, no ano de 2008, foi instituído o Piso Salarial Profissional Nacional, com o valor inicial de $\mathrm{R} \$ 950,00$ para jornada semanal de 40 horas. Em Minas Gerais, para uma jornada de 24 horas, o valor foi reduzido para $\mathrm{R} \$ 850,00 \mathrm{com}$ a inclusão de todos os abonos e adicionais existentes. Instituiu-se também, em Minas, a Parcela Compensatória Remuneratória do MagistérioPCRM, um montante necessário para atingir a remuneração de $R \$ 850,00$ (BRASIL, 2008).

Em 2010, deflagrou-se uma greve dos professores com 47 dias de paralisação em função de uma proposta com baixo índice de correção salarial enviado pelo governador, Antonio Anastasia, à Assembleia Legislativa de Minas Gerais. Nesse ano, o PSPN estipulado pelo Governo Federal era no valor de $\mathrm{R} \$ 1.024,67$. No entanto, a Secretaria de Estado de Educação de Minas Gerais pagava a remuneração de $\mathrm{R} \$ 935,00$ aos professores com todos os adicionais.

Como os conflitos intensificaram, o governador mineiro apresentou a Lei $n^{\circ} 18.975$, de 29 de junho de 2010, regulamentada pelo Decreto $n^{\circ} 45.527$, de 31 de dezembro de 2010 (MINAS GERAIS, 2010), alterando a forma de pagamento dos servidores do estado e instituindo, a partir de então, a remuneração por subsídio ${ }^{5}$. Em 2 de dezembro de 2011, entrou em vigor a Lei Estadual n 19.837 (MINAS GERAIS, 2011), que fixou o pagamento obrigatório do subsídio a todos os professores.

Em movimento contrário a essa política de governo, o Sind-UTE/MG e os professores lutavam pelo cumprimento das Metas 17 e 18 do projeto do Plano Nacional de Educação, que fixou como objetivo a valorização dos profissionais do magistério das redes públicas de educação básica, de forma a equiparar seu rendimento médio aos demais profissionais com escolaridade equivalente. A Meta 18 estabeleceu ainda a necessidade da existência de Planos de Carreira para os profissionais de educação básica pública.

Com a vigência dessa lei estadual, os professores foram reposicionados para o novo plano de carreira, em que o valor mínimo para a carreira de professor era de $\mathrm{R} \$ 712,20$ e o valor máximo seria de $\mathrm{R} \$ 1.575,73$. A implementação do posicionamento ocorreu em etapas, entre $1^{\circ}$ de janeiro de 2012 e $1^{\circ}$ de janeiro de 2015 . A política de valorização da profissão de professor é evidenciada na Lei Estadual n 19.837, de 2011, pois os salários fixados por esse plano de carreira para a categoria mineira foram menores que o fixado pela Lei Federal do Piso que era de $\mathrm{R} \$ 1.187,00$.

5 Subsídio corresponde a uma parcela única no pagamento do vencimento, incorporando todas as gratificações e vantagens em uma única rubrica (DI PIETRO, 2001). 
Os Ordenados Pagos aos Professores de Primeiras Letras às Políticas de Valorização Profissional e Social

\section{Considerações Finais}

No estado de Minas Gerais, as baixas remunerações e a falta de incentivo para a carreira docente eram justificadas pela impossibilidade financeira do governo estadual com as despesas do estado. A situação vivenciada pelos professores mineiros não se mostrou distante da realidade nacional, pelo contrário, historicamente, trilha o mesmo percurso. Os professores primários no estado de Minas Gerais têm tido salários baixos, precários planos de carreiras, jornadas duplas ou triplas e ordenados menores que os de outras categorias (ADÃO, 1997). A realidade profissional, dos professores mineiros foi historicamente marcada por ordenados inferiores - comparados a outros profissionais de escolaridade similar -, falta de condições de trabalho e ausência de valorização da carreira docente (SALES, 2000; NASCIMENTO, 2003).

Essas situações revelam como os professores do estado de Minas Gerais têm sido explorados e desvalorizados, sem ter salários dignos, prestígio social, condições adequadas de trabalho e estímulo à formação continuada.

O contexto histórico dos professores primários demonstra que foram submetidos à desvalorização socioeconômica e a condições de trabalho inadequadas. Constata-se que, independentemente do governo no poder, as crises econômicas e a falta de recursos são utilizadas pelas autoridades locais como justificativas para o não pagamento de um salário digno aos professores. Entre 1980 e 2014, as tensões e o enfrentamento entre governo e professores explodiram, marcando a luta pelos direitos sociais.

Alguns elementos desse percurso histórico das políticas públicas de valorização voltadas aos professores primários contribuem para apreender as contradições num movimento contínuo de ações do estado para viabilizar o modo de produção capitalista e, ao mesmo tempo, fixar valor pago ao trabalho dos professores e garantir alguns direitos. No entanto, quando os governos do estado argumentavam que enfrentavam crises e ausência de recursos financeiros, contraditoriamente pagavam melhor a outras categorias com mesmo nível de escolaridade, ou reajustavam os salários com porcentagem maior a outras categorias em detrimento à carreira de magistério (FARIA FILHO, 1998; OLIVEIRA, 2004; 2008).

As políticas de valorização dos governos mineiros para o trabalho docente mostram a continuidade da indiferença com a carreira, conforme afirma Oliveira (2008), com flexibilização das regras de contratação, menores salários, menor estabilidade, informalidade e menos direitos sociais.

\section{Referências}

ADÃO, Áurea. As Escolas Régias (1772-1794). Lisboa: Fundação Caouste Gulbenkian, 1997.

ANDRADE, Renata Fernandes Maia; CARVALHO, Carlos Henrique. A Educação no Brasil Império: análise da organização da instrução na Província de Minas Gerais (1850- 1889). História da Educação, Porto Alegre, v. 13, n. 28 p. 105-133, maio, 2009.

ANTUNES, Ricardo. Adeus ao Trabalho? Ensaio sobre as Metamorfoses e a Centralidade do Mundo do Trabalho. São Paulo: Cortez, 1997.

ASSOCIAÇÃO de Professores Públicos de Minas Gerais. Atas. Belo Horizonte, 1931-1939. 
Os Ordenados Pagos aos Professores de Primeiras Letras às Políticas de Valorização Profissional e Social

BONACINI, Irma Luiz. A Maior Aula em Praça Pública: trabalho, política e imaginário das professoras primárias em Minas Gerais (1979-1980). Campinas: UNICAMP, 1992.

BRASIL. Lei de 15 de outubro de 1827. Diário Oficial [da República Federativa do Brasil], Brasília, 1827.

BRASIL. Lei $n^{0}$ 5.692, de 11 de agosto de 1971. Fixa as Diretrizes e Bases para o ensino de $1^{\circ}$ e $2^{\circ}$ graus, e dá outras providências. Diário Oficial [da República Federativa do Brasil], Brasília, 1971.

BRASIL. O Plano de Desenvolvimento da Educação: razões, princípios e programas. Brasília: Ministério da Educação, 2007.

BRASIL. Lei $n^{\circ} 11.738$, de 16 de julho de 2008. Regulamenta a Alínea "e" do Inciso III do Caput do art. 60 do Ato das Disposições Constitucionais Transitórias, para Instituir o Piso Salarial Profissional Nacional para os Profissionais do Magistério Público da Educação Básica. Diário Oficial da União, Brasília, 2008.

CARDOSO, Tereza Maria Rolo Fachada Levy. As Luzes da Educação. Bragança Paulista: EDUSF, 2002.

CARRATO, José Ferreira. Igreja, Iluminismo e Escolas Mineiras Coloniais: notas sobre a cultura da decadência mineira setecentista. São Paulo: EDUSP, 1968.

COSTA, Gilvan Luiz Machado; OLIVEIRA, Dalila Andrade. O Trabalho Docente no Ensino Médio no Brasil: sujeitos e condições singulares. In: GOUVEIA, Andréa Barbosa; PINTO, José Marcelino de Rezende; CORBUCCI, Paulo Roberto (Org.). Federalismo e Políticas Educacionais na Efetivação do Direito à Educação no Brasil. Brasília: Ipea, 2011.

COSTA, Antônio Luiz Monteiro Coelho. As Reencarnações da Moeda Brasileira. 2017. Disponível em: <http://antonioluizcosta.sites.uol.com.br/moeda_brasil. htm\#chegabrasil>. Acesso em: 19 jul. 2017.

CURY, Carlos Roberto Jamil. A Educação como Desafio na Ordem Jurídica. In: LOPES, Eliane Marta Santos Teixeira; FARIA FILHO, Luciano Mendes de; VEIGA, Cynthia Greive. 500 Anos de Educação no Brasil. Belo Horizonte: Autêntica, 2000.

DI PIETRO, Maria Zanella. As Novas Regras para os Servidores Públicos. Cadernos FUNDAP, São Paulo, n. 22, 2001, p. 27-39.

DURÃES, Sarah Jane Alves. Escolarização das Diferenças: qualificação do trabalho docente e gênero em Minas Gerais (1860-1906). São Paulo: Pontifícia Universidade Católica de São Paulo, 2002.

FARIA FILHO, Luciano Mendes. Culturas e Práticas Escolares: escrita, aluno e corporeidade. Cadernos de Pesquisa, São Paulo, n 103, p. 136-149, mar. 1998.

FARIA FILHO, Luciano Mendes. Educação e Modernidade: a estatística como estratégia de conformação do campo pedagógico brasileiro (1850-1930). Educação e Filosofia, Uberlândia, n. 28, p. 175-201, jun. 2000.

FERNANDES, Rogério. Os Caminhos do ABC. Porto: Porto, 1994. 
Os Ordenados Pagos aos Professores de Primeiras Letras às Políticas de Valorização Profissional e Social

GONÇALVES, Irlen Antônio. Cultura Escolar: práticas e produção dos grupos escolares em Minas Gerais (1891-1918). 2004. 282 f. Tese (Doutorado em Educação), Faculdade de Educação, Universidade Federal de Minas Gerais, Belo Horizonte, 2004.

GONÇALVES, Irlen Antônio. Cultura Escolar: práticas e produção dos grupos escolares em Minas Gerais. Belo Horizonte: Autêntica, 2006.

GUIMARÃES, Vicente. A Literatura Infantil e as Professoras Primárias. Educando, Belo Horizonte, $n^{\circ} 3,1940$.

GUIMARÃES; PORDEUS; CAMPOS (Org.). Estado para Resultados: avanços no monitoramento e avaliação da gestão pública em Minas Gerais. Belo Horizonte: Editora UFMG, 2010.

HILSDORF, Maria Lúcia. Mestra Benedita Ensina Primeiras Letras em São Paulo (1828-58). In: CONGRESSO LUSO-BRASILEIRO DE HISTÓRIA DA EDUCAÇÃO: LEITURA E ESCRITA EM PORTUGAL E NO BRASIL (1500-1970), 1., 1998, Lisboa. Anais... Lisboa: Sociedade Portuguesa de Ciências da Educação, 1998.

KUENZER, Acácia Zeneida. As Políticas de Formação: a constituição da identidade do professor sobrante. Educação e Sociedade, Campinas, v. 20, n. 68, p. 163-183, 1999.

KULESZA, Wojciech Andrzej. A Institucionalização da Escola Normal no Brasil (1870 - 1910). Revista Brasileira de Estudos Pedagógicos, Brasília, v. 79, n. 193, 1998.

MACHADO, José Timóteo Montalvão. II Centenário da Instrução Primária. Lisboa: Ministério da Educação Nacional, 1972.

MAGALHÃES, Jussara Maria de Pinho. Projeto Veredas, Desenvolvimento Profissional e Exercício da Docência: ouvindo professoras cursistas e seu tutor. Belo Horizonte, 2005.

MANIFESTO dos Professores Públicos Primários da Corte. Rio de Janeiro: J. Villeneuve e Cia, 1871.

MONLEVADE, João Antônio Cabral de. Valorização Salarial dos Professores: o papel do piso salarial profissional nacional como instrumento de valorização dos professores de educação básica pública. Campinas: UNICAMP, 2000

MINAS GERAIS. Lei $n^{0} 13$, de 13 de março de 1835. Regula a Criação das Cadeiras de Instrução Primária, o Provimento, e os Ordenados dos Professores. Microfilme, Arquivo Público Mineiro, Caixa nº 1 1835-1851, Belo Horizonte, 1835.

MINAS GERAIS. Regulamento $n^{\circ} 41$, de 16 de maio de 1857. Coleção de Leis, Resoluções e Regulamentos da Província de Minas Gerais, Belo Horizonte, 1857.

MINAS GERAIS. Decreto $n^{\circ}$ 516, de 12 de junho de 1891. Assembleia Legislativa de Minas Gerais, Belo Horizonte, 1891.

MINAS GERAIS. $\quad$ Mensagem $1896 . \quad$ Disponível em: <www.crl.uchicago.edu/info/brazil/pindex.htm>. Acesso em: 01 jul. 2016.

MINAS GERAIS. Lei $n^{\circ} 281$, de 16 de setembro de 1899. Dá Nova Organização à Instrução Primária do Estado de Minas. Assembleia Legislativa de Minas Gerais, Belo Horizonte, 1899. 
Os Ordenados Pagos aos Professores de Primeiras Letras às Políticas de Valorização Profissional e Social

MINAS GERAIS. $\quad$ Mensagem $1899 . \quad$ Disponível em: <www.crl.uchicago.edu/info/brazil/pindex.htm>. Acesso em: 01 jul. 2016.

MINAS GERAIS. Decreto $\mathrm{n}^{\circ} 1.348$, de 8 de janeiro de 1900. Assembleia Legislativa de Minas Gerais, Belo Horizonte, 1900.

MINAS GERAIS. Lei $n^{\circ} 439$, de 28 de setembro de 1906. Autoriza o Governo a Reformar o Ensino Primário, Normal e Superior do Estado, e dá outras Providências. Assembleia Legislativa de Minas Gerais, Belo Horizonte, 1906.

MINAS GERAIS. Lei $n^{\circ} 752$ de 27 de setembro de 1919. Dispõe sobre o Ensino Primário e Normal do Estado. Coleção das leis e decretos do estado de Minas Gerais, Belo Horizonte, 1919.

MINAS GERAIS. Lei $n^{\circ}$ 800, de 27 de setembro de 1920. Reorganiza o Ensino Primário do Estado e Contém outras Disposições. Assembleia Legislativa de Minas Gerais, Belo Horizonte, 1919.

MINAS GERAIS. Decreto $n^{\circ}$ 9.892, de 18 de março de 1931. Assembleia Legislativa de Minas Gerais, Belo Horizonte, 1931.

MINAS GERAIS. Lei n 869 , de 05 de julho de 1952. Dispõe sobre o Estatuto dos Funcionários Públicos Civis do estado de Minas Gerais. Assembleia Legislativa de Minas Gerais, Belo Horizonte, 1952.

MINAS GERAIS. Relatório de Gestão 1999/2002. Coleção das leis e decretos do estado de Minas Gerais, Belo Horizonte, 2002.

MINAS GERAIS. Lei n 15.293 de 05 de agosto de 2004. Institui as Carreiras dos Profissionais de Educação Básica do Estado. Diário do Executivo, Belo Horizonte, 2004.

MINAS GERAIS. Lei $n^{\circ} 15.784$, de 27 de outubro de 2005. Estabelece as Tabelas de Vencimento Básico das Carreiras dos Profissionais de Educação Básica e das Carreiras do Grupo de Atividades de Defesa Social, a que se Referem os Incisos VII a XI do Art. $1^{\circ}$ da Lei $\mathrm{n}^{\circ}$ 15.301, de 10 de Agosto de 2004, os seus Reajustamentos e Dispõe sobre a Vantagem Temporária Incorporável - VTI - e o Posicionamento dos Servidores nas Referidas Carreiras. Diário do Executivo, Belo Horizonte, 2005.

MINAS GERAIS. Decreto $n^{\circ} 45.527$, de 31 de janeiro de 2010. Assembleia Legislativa de Minas Gerais, Belo Horizonte, 2010.

MINAS GERAIS. Lei $n^{\circ}$ 19.837, DE 02 DE DEZEMBRO DE 2011. Promove Alterações Na Política Remuneratória das Carreiras do Grupo de Atividades da Educação Básica e das Carreiras do Pessoal Civil da Polícia Militar, e dá outras Providências. Assembleia Legislativa de Minas Gerais, Belo Horizonte, 2011.

NASCIMENTO, Cecília Vieira. Do Mestre-Escola à Professora: saberes e práticas docentes em seu processo de profissionalização - 1872/1906. In: CONGRESSO DE PESQUISA E ENSINO DE HISTÓRIA DA EDUCAÇÃO EM MINAS GERAIS, 2., 2003, Uberlândia. Anais... Uberlândia: UFU, 2003.

OLIVEIRA, Dalila Andrade. A Reestruturação do Trabalho Docente: precarização e flexibilização. Educação e Sociedade, Campinas, v. 25, n. 89, p. 1127-1144, set./dez., 2004. 
Os Ordenados Pagos aos Professores de Primeiras Letras às Políticas de Valorização Profissional e Social

OLIVEIRA, Dalila Andrade. La Cuestión Docente: Brasil, las condiciones laborales de los profesores de educación básica. Buenos Aires: Laboratório de Políticas Públicas, 2008.

PEIXOTO, Ana Maria Casasanta. Lições de Minas: 70 Anos da Secretaria de Educação do Governo de Minas. Belo Horizonte: Governo do Estado de Minas Gerais; Secretaria da Educação, 2000.

SALES, Luís Carlos. O Valor Simbólico do Prédio Escolar. Teresina: EDUFPI, 2000.

SALES, Zeli Efigênia Santos de. O Conselho Geral da Província e a Política de Instrução Pública em Minas Gerais (1825-1838). In: OLIVEIRA, Bernardo Jefferson de; VAGO, Tarcísio Mauro. Histórias de Práticas Educativas. Belo Horizonte: Editora UFMG, 2008. p. 81-96.

SAVIANI, Demerval. Formação de Professores: aspectos históricos e teóricos do problema no contexto brasileiro. Revista Brasileira de Educação, Rio de Janeiro, v. 14, n. 40, jan./abr. 2008.

SILVA, Eldra Carvalho da. Qualidade Social da Educação Pública: algumas aproximações. Caderno Cedes, Campinas, v. 29, n. 78, p. 216-226, maio/ago. 2009.

SUCUPIRA, Newton. O Ato Adicional de 1834 e a Descentralização da Educação. In: FÁVERO, Osmar (Org.). A Educação nas Constituintes Brasileiras: 1823-1988. Campinas: Editora Autores Associados, 1996.

TANURI, Leonor Maria. História da Formação de Professores. Revista Brasileira de Educação, Rio de Janeiro, n. 14, p. 61-88, maio/ago. 2000.

VIEIRA, Juçara Maria Dutra. Piso Salarial Nacional dos Educadores: dois séculos de atraso. Brasília: 2007.

Eduardo Ferreira da Silva Caetano é mestre em Educação pela Universidade de Brasilia (2015), Master Business Administration - MBA em Administração Pública pela Escola de Administração e Negócios ESAD (2013), graduado em Direito pelo Instituto Processus de Brasília (2017), graduado em Pedagogia pela Universidade de Brasília (2007). Atua na Subsecretária de Planejamento e Orçamento do Ministério da Educação desenvolvendo estudos e acompanhamentos orçamentários e jurídicos das Universidades e Institutos Federais. Servidor do Instituto Federal de Brasília cedido ao Ministério da Educação.

E-mail: eduardofscaetano@gmail.com 


\section{Editores do volume 7}

José Marcelino de Rezende Pinto - Universidade de São Paulo, São Paulo/SP, Brasil

Nalú Farenzena - Universidade Federal do Rio Grande do Sul, Porto Alegre/RS, Brasil

\section{Comitê Editorial}

José Marcelino de Rezende Pinto - Universidade de São Paulo, Brasil

Juca Gil - Universidade Federal do Rio Grande do Sul, Brasil

Theresa Adrião - Universidade Estadual de Campinas, Brasil

Ângelo Ricardo de Souza - Universidade Federal do Paraná, Brasil

Márcia Aparecida Jacomini - Universidade Federal de São Paulo, Brasil

\section{Conselho Editorial}

\section{Alejandro Morduchowicz}

Universidad Pedagógica, Provincia de Buenos Aires, Argentina

Fernanda Saforcada

Universidade de Buenos Aires, Argentina

Jacques Velloso

Universidade de Brasília, Brasil

João Monlevade

Senado Federal, Brasil

Jorge Abrahão de Castro

Instituto de Pesquisa Econômica Aplicada / IPEA, Brasil

Juca Gil

Universidade Federal do Rio Grande do Sul, Brasil

Lisete Regina Gomes Arelaro

Universidade de São Paulo, Brasil

Luis Carlos Sales

Universidade Federal do Piauí, Brasil

Luiz de Sousa Junior

Universidade Federal da Paraíba, Brasil

Luiz Fernandes Dourado

Universidade Federal de Goiás, Brasil

Magna França

Universidade Federal do Rio Grande do Norte, Brasil

Maria Beatriz Luce

Universidade Federal do Pampa, Brasil

Universidade Federal do Rio Grande do Sul, Brasil

Marcos Edgar Bassi

Universidade Federal do Paraná, Brasil

Maria Dilnéia Espíndola Fernandes

Universidade Federal de Mato Grosso do Sul, Brasil

\section{Nalú Farenzena}

Universidade Federal do Rio Grande do Sul, Brasil

Nelson Cardoso do Amaral

Universidade Federal de Goiás, Brasil

Nicholas Davies

Universidade Federal Fluminense, Brasil

Rosana Evangelista Cruz

Universidade Federal do Piauí, Brasil

Rosana Gemaque

Universidade Federal do Pará, Brasil

Robert E. Verhine

Universidade Federal da Bahia, Brasil

Romualdo Portela de Oliveira

Universidade de São Paulo, Brasil

Theresa Adrião

Universidade Estadual de Campinas, Brasil

Tristan McCowan

University of London, Reino Unido

Vera Jacob

Universidade Federal do Pará, Brasil

Vera Peroni

Universidade Federal do Rio Grande do Sul, Brasil

Vitor Henrique Paro

Universidade de São Paulo, Brasil

\section{Equipe editorial}

Apoio ao Comitê Editorial: Patrícia Balthazar Garcia

Diagramação, Revisão de português e normalização: Edson Leonel de Oliveira

Revisão de inglês: Ananyr Porto Fajardo 